\title{
Impairment of Laryngeal Elevation
}

National Cancer Institute

\section{Source}

National Cancer Institute. Impairment of Laryngeal Elevation. NCI Thesaurus. Code C127231.

An observation of an individual's larygeal elevation during swallowing. 